\title{
Artigo Original / Original Paper Agrupamento e caracterização anatômica da madeira de espécies nativas da Floresta Ombrófila Mista
}

\author{
Anatomical grouping and characterization of wood of native species of the Araucaria Forest
}

\author{
Helena Cristina Vieira ${ }^{1,3}$, Polliana D`Angelo Rios ${ }^{1}$, Teresa Maria Gonçalves Quilhó Marques dos Santos², \\ Alexsandro Bayestorff da Cunha ${ }^{1}$, Martha Andrea Brand ${ }^{1}$, Dianessa Danielli ${ }^{1}$, Jeimy Blanco Florez ${ }^{1}$, \\ Rafaela Stange ${ }^{1}$, Rodrigo Buss ${ }^{1} \&$ Pedro Higuchi ${ }^{1}$
}

\begin{abstract}
Resumo
Na Floresta Ombrófila Mista adicionalmente à diversidade florística, estudos sobre a diversidade anatômica da madeira de espécies nativas são interessantes pois permitem ampliar nosso conhecimento sobre a flora local. Portanto, este trabalho objetivou caracterizar anatomicamente e avaliar as similaridades e as principais características anatômicas que variam entre a madeira de 14 espécies nativas da Floresta Ombrófila Mista, de acordo com IAWA (1989). Foram utilizadas 14 variáveis anatômicas para aplicar os métodos de similaridade de Manhattan e Análise de Componentes Principais (PCA). Como resultados, pode-se observar que as espécies apresentam características comuns, como a porosidade difusa e pontoações intervasculares alternas. Além disso, a presença de fibras septadas e parênquima axial escasso em $50 \%$ das madeiras, foram características marcantes para as espécies da região. Quanto à similaridade, observou-se a divisão das mesmas pelas dimensões dos raios, vasos e pontoções. No PCA, destacaram-se o diâmetro do vaso, largura e altura do raio, a altura do raio em número de células, as pontoações intervasculares e raio-vasculares. Pode-se concluir que, mesmo com a grande diversidade anatômica é possível diferenciar a madeira das espécies da Floresta Ombrófila Mista, que ocorrem naturalmente na região do Planalto Catarinense.
\end{abstract}

Palavras-chaves: diversidade anatômica, estrutura da madeira, floresta com araucária.

\begin{abstract}
In the Araucaria Forest in addition to floristic diversity, studies on the anatomical diversity of wood of native species are required. Therefore, this work aimed to characterize anatomically and evaluate the similarities and the main anatomical characteristics that vary between the wood of 14 native species of the Araucaria Forest. For the characterizations, the procedures determined by IAWA (1989) were followed. Fourteen anatomical variables were used to apply the Manhattan similarity and Principal Component Analysis (PCA). As result, it can be observed that the species present common characteristics, such as diffuse porosity and alternate intervessel pits. In addition, the presence of septate fibers and axial parenchyma scarce in $50 \%$ of the woods were remarkable characteristics for the species of the region. As for the similarity, was observed the division by the dimensions of the rays, vessels and pits. In PCA, the diameter of the vessel, width and height of the radius, the height of the radius in number of cells, the intervessel pits and the radius-vascular were emphasized. In conclusion, even with the great anatomical diversity, it is possible to differentiate the wood from the species of the Araucaria Forest, which occur naturally in the region of Planalto Catarinense.
\end{abstract} Key words: anatomical diversity, structure of wood, Araucarian forest.

\footnotetext{
${ }^{1}$ Universidade do Estado de Santa Catarina - UDESC, Centro de Ciências Agroveterinárias - CAV, Av. Luiz de Camões 2.090, Conta Dinheiro, 88520-000, Lages, SC, Brasil.

${ }^{2}$ Instituto Superior de Agronomia - ISA, Tapada da Ajuda, 1349-017, Lisboa, Portugal.

${ }^{3}$ Autor para correspondência: lenacristin@hotmail.com
} 


\section{Introdução}

A Floresta Ombrófila Mista é conhecida popularmente como Mata das Araucárias, Pinhal ou Floresta com Araucária (Hueck 1972; Guerra et al. 2002). Esta floresta possui ocorrência natural entre os paralelos $21^{\circ}$ e $30^{\circ} \mathrm{S}$ e entre os meridianos $44^{\circ}$ e $54^{\circ} \mathrm{O}$. No Brasil, são encontrados cerca de 20 mil hectares de remanescentes nos estados de Santa Catarina, Rio Grande do Sul, Paraná, Minas Gerais e São Paulo (Inoue et al. 1984; Britez et al. 1992). Devido à sua ampla extensão territorial, a Floresta Ombrófila Mista possui grande importância pelo seu alto valor ecológico, pois além de abrigar diversas espécies típicas, possui a estrutura complexa, com grande diversidade florística (Eisenlohr \& Oliveira Filho 2014; Nascimento et al. 2001).

Atualmente, sabe-se que estas regiões que apresentam áreas com alta biodiversidade exigem a realização de inventários e caracterizações que definam a diversidade florística da região (Cury 2001). Souza et al. (1990) afirmam que uma das alternativas para identificar esta diversidade, é o estudo da similaridade, que é um método empregado como ferramenta que analisa o comportamento dos dados e encontra padrões ou agrupamentos para diferentes espécies.

Utilizando o agrupamento de espécies é possível identificar as características comuns para regiões, tipologias florestais, famílias, gêneros, espécies, usos e adaptações fisiológicas. No Brasil, Lobão et al. (2010) realizaram o agrupamento de espécies florestais nativas, de acordo com as características físicas e anatômicas da madeira. Pesquisas também foram realizadas considerando a madeira do gênero Psychotria L. (Marques et al. 2015), espécies de lianas (Brandes \& Barros 2008), o gênero Eugenia L. (Marques et al. 2007), a família Euphorbiaceae (Siegloch et al. 2013), e espécies da Floresta Ombrófila Mista no Paraná (Soffiatti et al. 2016). Contudo, ainda são poucos os estudos publicados.

Portanto, devido a necessidade de pesquisas que analisem a diversidade das espécies nativas do estado de Santa Catarina, este trabalho objetivou caracterizar anatomicamente a madeira de 14 espécies nativas (Campomanesia xanthocarpa Berg, Citronella paniculata (Mart.) R.A.Howard, Cupania vernalis Cambess., Eugenia pyriformis Cambess., Inga vera Willd., Machaerium paraguariense Hassl., Myrsine coriacea (Sw.) R.Br. ex Roem. \& Schult., Nectandra megapotamica (Spreng.) Mez, Ocotea indecora (Schott) Mez, Ocotea diospyrifolia
(Meisn.) Mez, Picrasma crenata (Vell.) Engl., Piptocarpha angustifolia Dusén ex Malme, Schinus terebinthifolius Raddi e Zanthoxylum rhoifolium) Lam.) da Floresta Ombrófila Mista, além de avaliar sua diversidade e os componentes principais das suas estruturas anatômicas.

\section{Material e Métodos}

Para as caracterizações, foram utilizadas amostras de madeiras cedidas pelo Instituto Brasileiro do Meio Ambiente e dos Recursos Naturais Renováveis (IBAMA), de uma região que daria lugar ao reservatório da Usina Hidrelétrica de São Roque. Aárea abrange as cidades de Campos Novos, Brunópolis, Curitibanos, Frei Rogério, São José do Cerrito e Vargem, no estado de Santa Catarina.

Selecionaram-se aleatoriamente três árvores de cada espécie. De cada árvore foi retirado material botânico para o registro, identificação botânica e armazenamento no Herbário de Lages, da Universidade do Estado de Santa Catarina (LUSC), além de um disco do tronco principal com $10 \mathrm{~cm}$ de espessura, o qual foi coletado na altura do peito (1,30 metros do solo).

Foram utilizadas as madeiras de 14 espécies de Angiospermas escolhidas aleatoriamente na região. As famílias mais presentes foram a Lauraceae (3 espécies), Fabaceae (2 espécies) e Myrtaceae (2 espécies). Na Tabela 1, estão listadas as espécies caracterizadas, com seus respectivos nomes populares, famílias e número de registro no Herbário LUSC.

Foram retirados 2 corpos de prova com $2 \times 2 \times 2 \mathrm{~cm}$ de altura, largura e comprimento, de cunhas opostas da região intermediária entre a medula e a casca dos discos. Posteriormente, utilizando o micrótomo de deslize, obteve-se os cortes histológicos com espessura média de $16 \mu \mathrm{m}$. A confecção das lâminas permanentes seguiu o descrito por Kraus \& Arduin (1997).

O material macerado foi confeccionado de acordo com Franklin (1945). Para todos os parâmetros quantitativos, foram feitas 40 mensurações para cada amostra, totalizando 240 medidas por parâmetro em cada espécie. Todas as medições foram feitas seguindo o descrito por Paula \& Alves (2010), utilizando o Microscópio Leica DM500, dotado de câmera Leica ICC50 HD e software Leica Módulo Leica LAS Interactive Measurements. A Tabela 2 apresenta os parâmetros que foram mensurados para as espécies e a seção de observação. 
Tabela 1 - Informações dos indivíduos utilizados para a caracterização anatômica.

Table 1 - Information of the individuals used for the anatomical characterization.

\begin{tabular}{|c|c|c|c|}
\hline Espécie & Nome popular & Família & Número do Registro \\
\hline Campomanesia xanthocarpa Berg & Guabiroba & Myrtaceae & LUSC $6188,6189,6190$ \\
\hline Citronella paniculata (Mart.) R.A.Howard & Congonha & Cardiopteridaceae & LUSC 6207, 6208, 6209 \\
\hline Cupania vernalis Cambess. & $\begin{array}{l}\text { Camboatá- } \\
\text { vermelho }\end{array}$ & Sapindaceae & LUSC $6213,6214,6215$ \\
\hline Eugenia pyriformis Cambess. & Uvaia & Myrtaceae & LUSC 6219, 6220, 6221 \\
\hline Inga vera Willd. & Ingá & Fabaceae & LUSC $6225,6226,6227$ \\
\hline Machaerium paraguariense Hassl. & Jacaranda-branco & Fabaceae & LUSC 6243, 6244, 6245 \\
\hline Myrsine coriacea (Sw.) R.Br. ex Roem. \& Schult. & Capororoca & Primulaceae & LUSC 6258, 6259, 6260 \\
\hline Nectandra megapotamica (Spreng.) Mez & Canela-imbuia & Lauraceae & LUSC 6264, 6265, 6266 \\
\hline Ocotea indecora (Schott) Mez & Canela & Lauraceae & LUSC 6267, 6268, 6269 \\
\hline Ocotea diospyrifolia (Meisn.) Mez & Canela & Lauraceae & LUSC $6270,6271, *$ \\
\hline Picrasma crenata (Vell.) Engl. & Pau-amargo & Simaroubaceae & LUSC $6285,6286,6287$ \\
\hline Piptocarpha angustifolia Dusén ex Malme & Vassourão-branco & Asteraceae & LUSC $6288,6289,6290$ \\
\hline Schinus terebinthifolius Raddi & Aroeira & Anacardiaceae & LUSC 6300, 6301, 6302 \\
\hline Zanthoxylum rhoifolium Lam. & Mamica de cadela & Rutaceae & LUSC 6321, 6322, 6323 \\
\hline
\end{tabular}

Tabela 2 - Parâmetros mensurados nos elementos anatômicos e a seção de observação. Table 2 - Parameters measured in the anatomical elements and the observation section.

\begin{tabular}{cc} 
Parâmetro & Observação \\
\hline Diâmetro tangencial dos vasos (VasoD) & Seção transversal \\
Número de vasos / $\mathrm{mm}^{2}$ (VasoF) & Seção radial \\
Pontoações raio-vasculares (PontRV) & \\
Pontoações intervasculares (PontV) & Seção tangencial \\
Altura dos raios (RaioCM) & \\
Altura dos raios (n⿳⺈ de células) (RaioCN) & \\
Largura dos raios (RaioEM) & \\
Largura dos raios (no de células) (RaioEN) & \\
Número de raios / mm (RaioF) & Elementos dissociados \\
Comprimento das fibras (FibraC) & \\
Espessura de parede das fibras (FibraEP) & \\
Largura das fibras (FibraLa) & \\
\hline
\end{tabular}

Para a caracterização, seguiu-se os procedimentos determinados pelo International Association of Wood Anatomists (IAWA 1989). Após a caracterização, as espécies foram agrupadas com base nas 14 variáveis quantitativas, por meio da similaridade de
Manhattan. Posteriormente, inferiu-se quais são as características anatômicas mais importantes para explicar a variância dos dados realizando a Análise dos Componentes Principais (PCA) no R (R Core Team 2015), utilizando o pacote Vegan (Oksanen et al. 2011). 


\section{Resultados e Discussão}

As Figuras 1, 2 e 3 apresentam, respectivamente, a anatomia do lenho nos planos transversal, tangencial e radial de todas as espécies caracterizadas. As descrições anatômicas das espécies estão apresentadas na Tabela 3. Com estas informações é possível afirmar que as características mais comuns para as espécies analisadas são: camada de crescimento distinta (Fig. 1h), porosidade difusa, vasos múltiplos de até 5, placa de perfuração simples, pontoações intervasculares alternas, raios heterocelulares, parênquima axial escasso e difuso.

Ainda, de acordo com a Tabela 3, pode-se observar que foram identificadas características comuns para todas espécies, sendo elas: porosidade difusa, elementos de vaso arredondados e pontoações intervasculares alternas. De forma similar, Soffiatti et al. (2016), estudando a estrutura anatômica das madeiras da Floresta Ombrófila Mista de espécies coletadas no Paraná encontraram em comum as seguintes características: anel de crescimento distinto, porosidade difusa, placa de perfuração simples, parênquima axial escasso e raios heterogêneos. Assim, pode-se observar que a diversidade da Floresta também é influenciada pelo local de coleta e pelas espécies selecionadas.

Considerando a composição dos raios, 93\% das espécies apresentaram raios heterocelulares, por serem compostos por células procumbentes na região central e células quadradas ou eretas nas margens. Somente a espécie $I$. vera apresentou raios homocelulares, formados somente por células procumbentes. A presença de raios homocelulares não foi comum para as espécies da região, contudo para outras tipologias florestais essa é uma característica frequente (Maiti et al. 2016).

Além disso, 43\% apresentaram a formação de cristais no parênquima radial e $36 \%$ possuem conteúdo no seu interior. Porém somente as espécies $M$. paraguariense, $O$. indecora e $N$. megapotamica apresentaram amido no interior das células. Cosmo et al. (2010), indicam que a presença de amido pode ocorrer devido à diversos fatores, dentre eles pode-se destacar os fatores genéticos e necessidade de reservas energéticas para diferentes períodos fisiológicos da árvore, como floração e produção de novas folhas.

Para os anéis de crescimento, aproximadamente $86 \%$ são distintos, este comportamento é comum para as regiões de altitudes elevadas, com estações bem definidas ao longo do ano (Burger \& Richter 1991). De acordo com Avila \& Oliveira (2017), a distinção dos anéis de crescimento possibilita a utilização das espécies de Lauraceae para a dendrocronologia. Neste estudo, apenas as espécies C. xantocarpa (Fig. 1a) e P. crenata (Fig. 1k) apresentaram anéis de crescimento indistintos ou de difícil reconhecimento.

Considerando o parênquima axial $50 \%$ das espécies apresentaram escasso, 43\% difuso, 36\% vasicêntrico, 29\% aliforme confuente (Fig. 1e), 21\% difuso agregado, $21 \%$ em faixas marginais, $21 \% \mathrm{em}$ faixas, 7\% vasicêntrico confluente e 7\% aliforme. Sendo que somente a espécie $P$. angustifolia apresentou o parênquima vasicêntrico confluente e a $I$. vera foi a única com parênquima axial aliforme.

Outro comportamento típico de espécies de regiões com altitudes elevadas e temperaturas mais baixas é a presença de fibras septadas, 50\% das espécies apresentaram fibras libriformes e septadas. Soffiatti et al. (2016), encontraram fibras septadas em 70\% das espécies estudadas na Floresta Ombrófila Mista no Paraná. De acordo com Carlquist (2001), esse comportamento ocorre devido à menor proporção de parênquima axial. Geralmente, nesses casos as fibras também apresentam como função o armazenamento de substâncias.

O tipo de agrupamento de vasos presente também variou entre as espécies. Sendo que 36\% apresentou vasos solitários e múltiplos de até 5 unidades, 29\% solitários e múltiplos até 4 unidades e $21 \%$ solitários e múltiplos de até 9 unidades. A espécie C. xanthocarpa é composta predominantemente de vasos solitários e a $E$. pyriformis é composta por vasos solitários e múltiplos de 2 e 3 unidades.

Ainda considerando os elementos vasculares foram observadas as seguintes características: a presença de tilos (O. indecora, $N$. megapotamica e $P$. angustifolia), conteúdo (óleos ou resinas) ( $P$. angustifolia, C. vernalis e $Z$. rhoifolium) e espessamento helicoidal ( $C$. vernalis e $P$. angustifolia).

Observou-se também a presença de placa de perfuração do tipo simples em todas as espécies e concomitantemente escalariforme em 29\% das espécies. Carquist (2001), ao avaliar o comportamento de diferentes espécies de acordo com a absorção de água, concluiu que espécies nativas de clima tropical apresentam placa de perfuração simples como um mecanismo para facilitar o transporte de água e solutos no lenho das árvores.

Algumas características são únicas para determinadas espécies, como a distribuição diagonal dos vasos (C. xanthocarpa), canais radiais $(S$. terebinthifolius)(Fig. $3 \mathrm{~m}$ ), raios agregados 

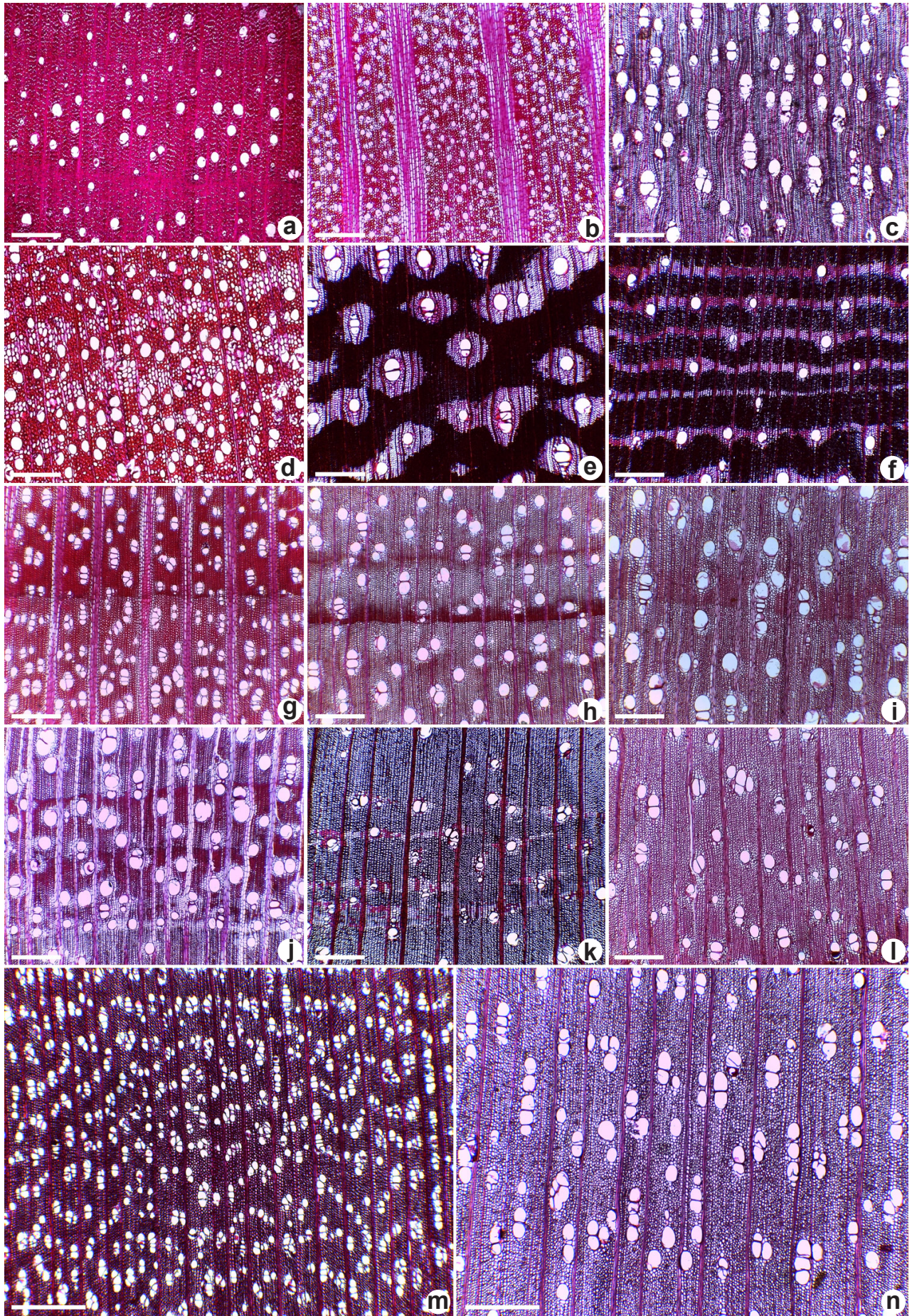

Figura 1 - a-n. Planos transversais das espécies caracterizadas - a. Campomanesia xanthocarpa; b. Citronella paniculata; c. Cupania vernalis; d. Eugenia pyriformis; e. Inga vera; f. Machaerium paraguariense; g. Myrsine coriacea; h. Nectandra megapotamica; i. Ocotea indecora; j. Ocotea diospyrifolia; k. Picrasma crenata; 1. Piptocarpha angustifolia; $\mathrm{m}$. Schinus terebinthifolius; $\mathrm{n}$. Zanthoxylum rhoifolium. Escala $=500 \mu \mathrm{m}$.

Figure 1 - a-n. Transverse planes of the species characterized - a. Campomanesia xanthocarpa; b. Citronella paniculata; c. Cupania vernalis; d. Eugenia pyriformis; e. Inga vera; f. Machaerium paraguariense; g. Myrsine coriacea; h. Nectandra megapotamica; i. Ocotea indecora $;$ j. Ocotea diospyrifolia $;$ k. Picrasma crenata $; 1$. Piptocarpha angustifolia $; \mathrm{m}$. Schinus terebinthifolius; $\mathrm{n}$. Zanthoxylum rhoifolium. Scale $=500 \mu \mathrm{m}$. 

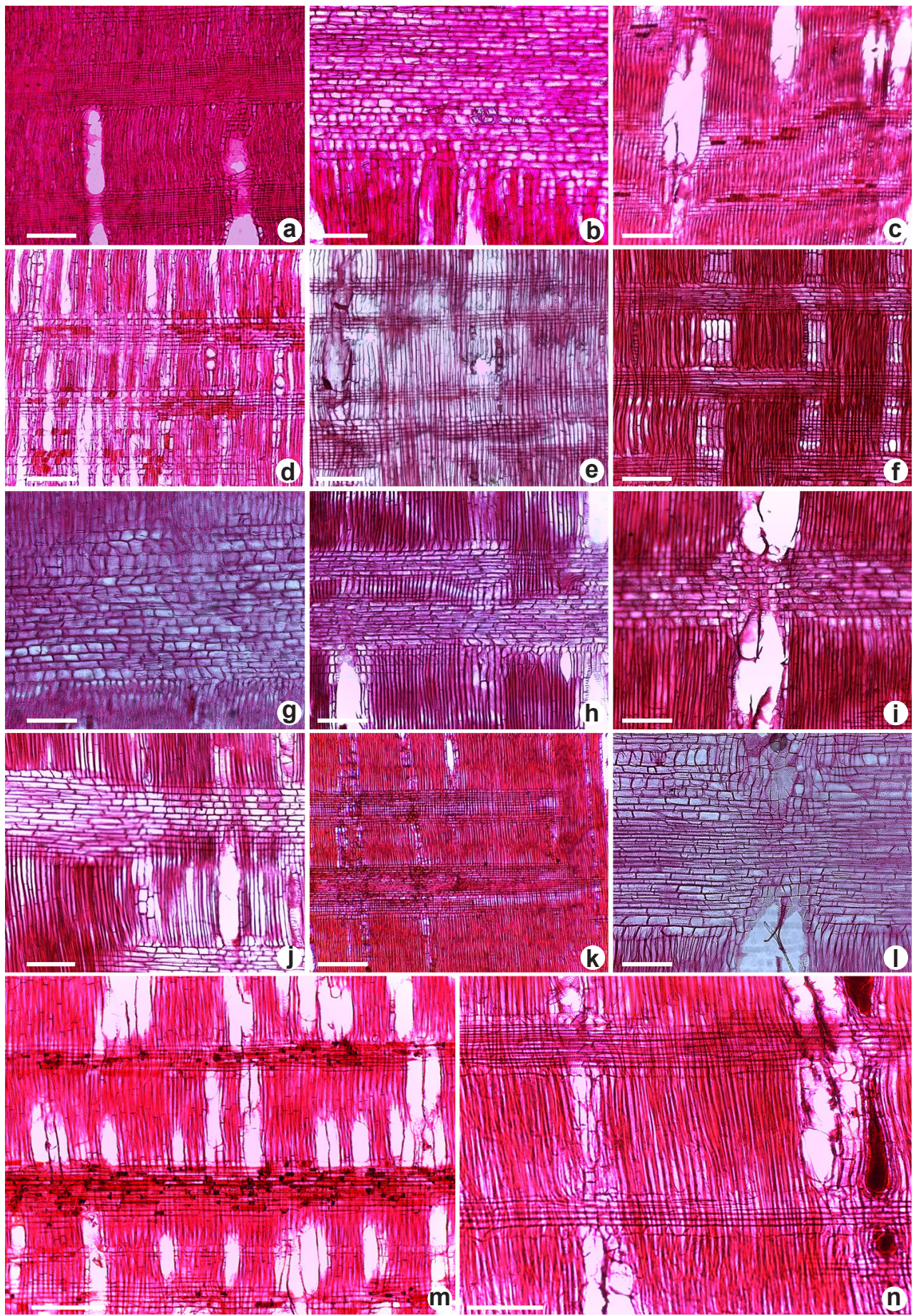

(k
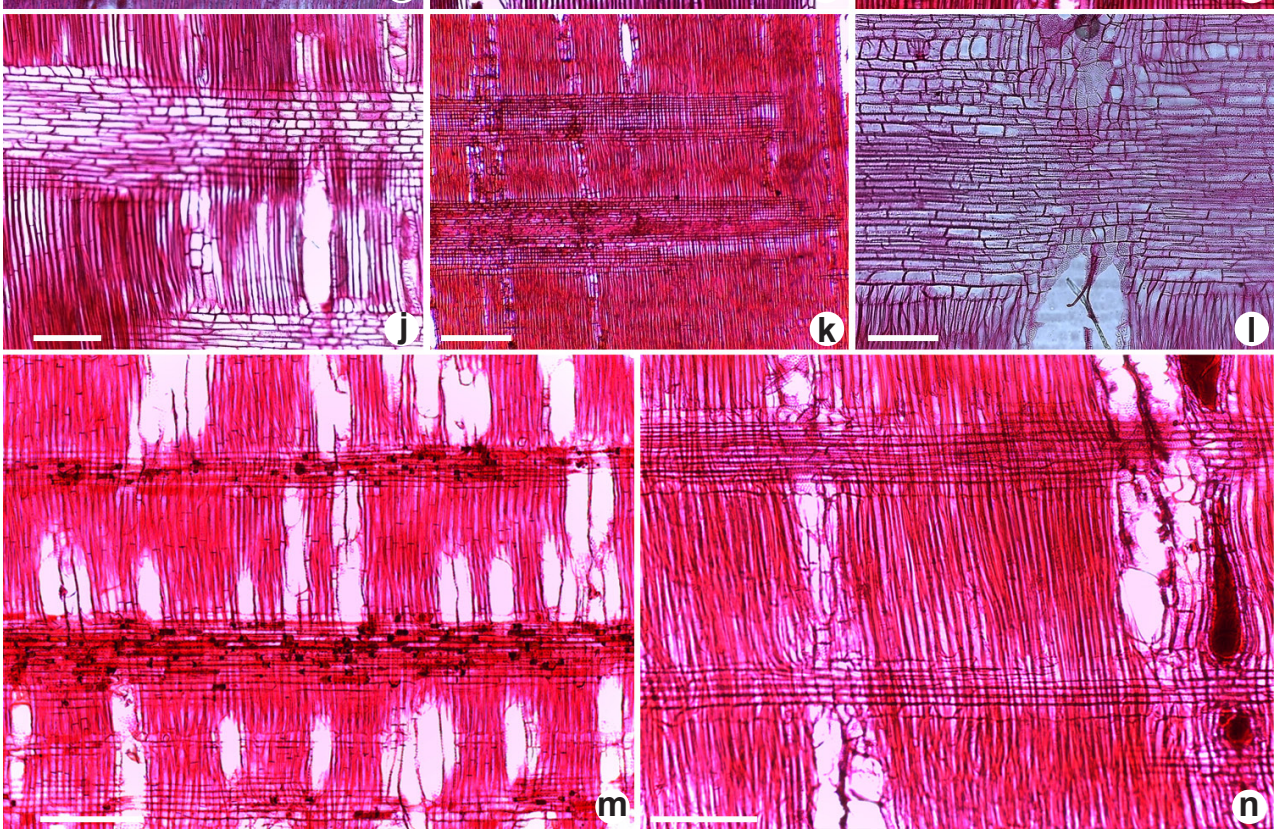

Figura 2 -a-n. Planos radiais das espécies caracterizadas - a. Campomanesia xanthocarpa; b. Citronella paniculata; c. Cupania vernalis; d. Eugenia pyriformis; e. Inga vera; f. Machaerium paraguariense; g. Myrsine coriacea; $\mathrm{h}$. Nectandra megapotamica; i. Ocotea indecora; j. Ocotea diospyrifolia; k. Picrasma crenata; 1 . Piptocarpha angustifolia; m. Schinus terebinthifolius; $\mathrm{n}$. Zanthoxylum rhoifolium. Escala $=200 \mu \mathrm{m}$.

Figure 2 - a-n. Radial planes of the species characterized - a. Campomanesia xanthocarpa; b. Citronella paniculata; c. Cupania vernalis; d. Eugenia pyriformis; e. Inga vera; f. Machaerium paraguariense; g. Myrsine coriacea; h. Nectandra megapotamica; i. Ocotea indecora; ;. Ocotea diospyrifolia $;$ k. Picrasma crenata; 1 . Piptocarpha angustifolia; m. Schinus terebinthifolius; n. Zanthoxylum rhoifolium. Scale $=200 \mu \mathrm{m}$. 

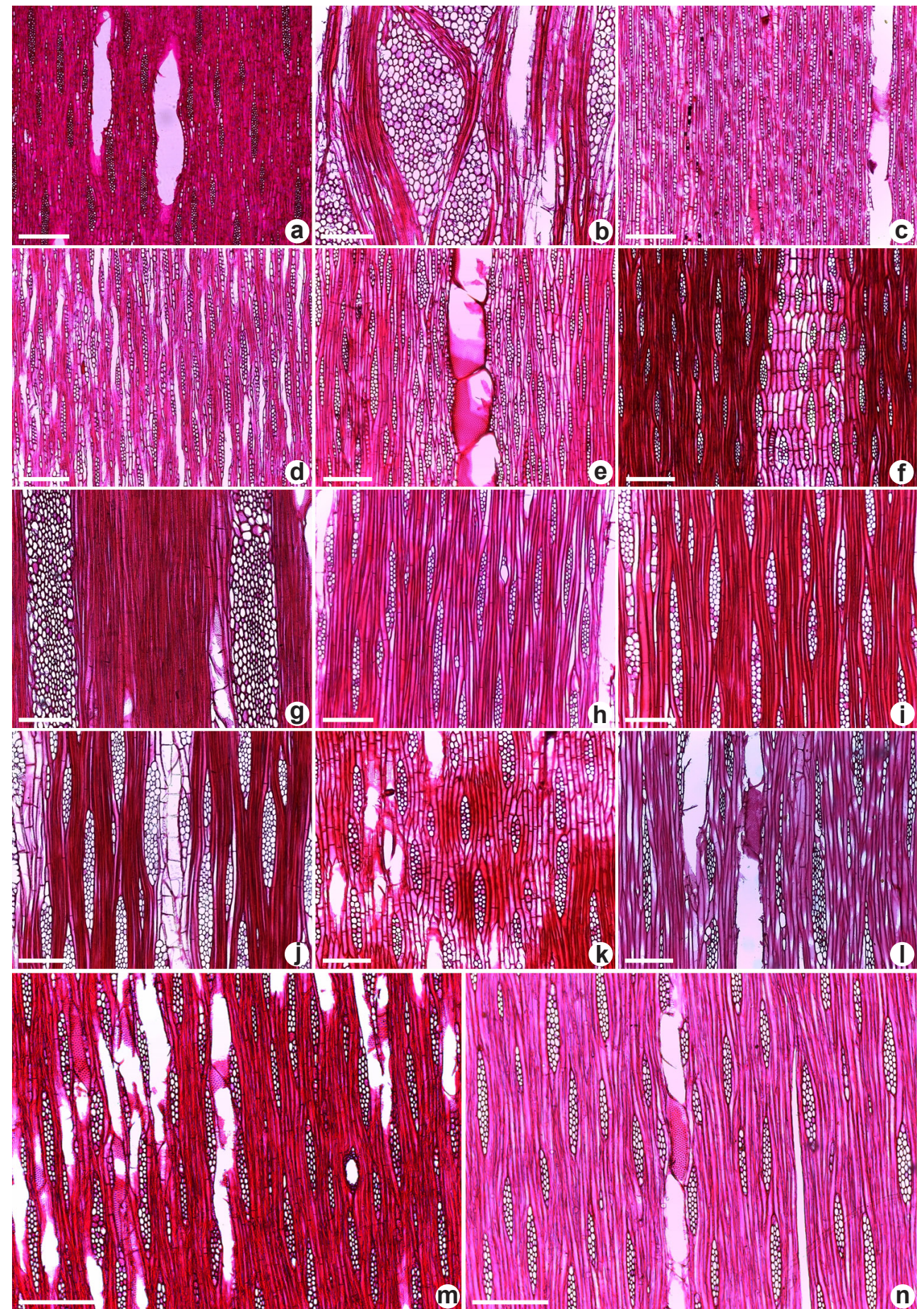

Figura 3 - a-n. Planos tangenciais das espécies caracterizadas - a. Campomanesia xanthocarpa; b. Citronella paniculata; c. Cupania vernalis; d. Eugenia pyriformis; e. Inga vera; f. Machaerium paraguariense; g. Myrsine coriacea; h. Nectandra megapotamica; i. Ocotea indecora; j. Ocotea diospyrifolia; k. Picrasma crenata; 1. Piptocarpha angustifolia; $\mathrm{m}$. Schinus terebinthifolius; $\mathrm{n}$. Zanthoxylum rhoifolium. Escala $=200 \mu \mathrm{m}$.

Figure 3 - a-n. Tangential planes of the characterized species - a. Campomanesia xanthocarpa; b. Citronella paniculata; c. Cupania vernalis; d. Eugenia pyriformis; e. Inga vera; f. Machaerium paraguariense; g. Myrsine coriacea; h. Nectandra megapotamica; i. Ocotea indecora $;$ j. Ocotea diospyrifolia $;$ k. Picrasma crenata $; 1$. Piptocarpha angustifolia $; \mathrm{m}$. Schinus terebinthifolius; $\mathrm{n}$. Zanthoxylum rhoifolium. Scale $=200 \mu \mathrm{m}$. 
Tabela 3 - Características qualitativas das espécies analisadas.

Table 3 - Qualitative characteristics of the species analyzed.

\begin{tabular}{|c|c|c|c|c|c|c|c|c|c|c|c|c|c|c|}
\hline & 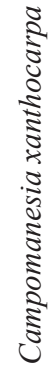 & 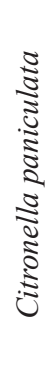 & 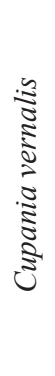 & 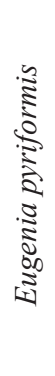 & $\begin{array}{l}5 \\
8 \\
0 \\
0 \\
0 \\
0 \\
0 \\
0\end{array}$ & 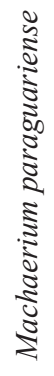 & 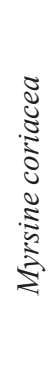 & 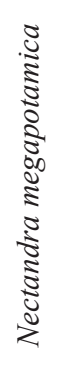 & 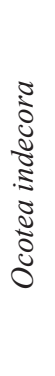 & 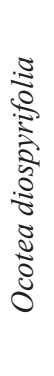 & 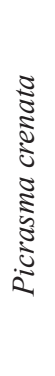 & 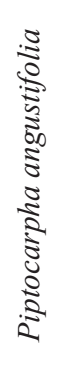 & 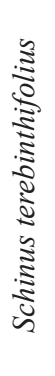 & 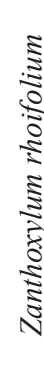 \\
\hline Anel com porosidade difusa & $\mathrm{x}$ & $\mathrm{x}$ & $\mathrm{x}$ & $\mathrm{x}$ & $\mathrm{x}$ & $\mathrm{x}$ & $\mathrm{x}$ & $\mathrm{x}$ & $\mathrm{x}$ & $\mathrm{x}$ & $\mathrm{x}$ & $\mathrm{x}$ & $\mathrm{x}$ & $\mathrm{x}$ \\
\hline Anel de crescimento distinto & & $\mathrm{x}$ & $\mathrm{x}$ & $\mathrm{x}$ & $\mathrm{x}$ & $\mathrm{x}$ & $\mathrm{x}$ & $\mathrm{x}$ & $\mathrm{x}$ & $\mathrm{x}$ & & $\mathrm{x}$ & $\mathrm{x}$ & $\mathrm{x}$ \\
\hline $\begin{array}{l}\text { Anel de crescimento indistintos ou de difícil } \\
\text { reconhecimento }\end{array}$ & $\mathrm{x}$ & & & & & & & & & & $\mathrm{x}$ & & & \\
\hline Canais intercelulares presentes & & & & & & & & $\mathrm{x}$ & & & & & & \\
\hline Canais radiais presentes & & & & & & & & & & & & & $\mathrm{x}$ & \\
\hline Cristais presentes no parênquima axial & & & $\mathrm{x}$ & $\mathrm{x}$ & $\mathrm{x}$ & & & & & & & $\mathrm{x}$ & & \\
\hline Cristais presentes nos raios & & $\mathrm{x}$ & $\mathrm{x}$ & & $\mathrm{x}$ & & $\mathrm{x}$ & & $\mathrm{x}$ & & & & $\mathrm{x}$ & \\
\hline Distribuição diagonal dos vasos & $\mathrm{x}$ & & & & & & & & & & & & & \\
\hline Estratificação completa da estrutura anatômica & & & & & & $\mathrm{x}$ & & & & & & & & \\
\hline Estratificação dos raios menores e das fibras & & & & & & & & & & & $\mathrm{x}$ & & & \\
\hline Fibras libriformes & $\mathrm{x}$ & & & $\mathrm{x}$ & & & $\mathrm{x}$ & & & & $\mathrm{x}$ & $\mathrm{x}$ & $\mathrm{x}$ & $\mathrm{x}$ \\
\hline Fibras libriformes septadas & & $\mathrm{x}$ & $\mathrm{x}$ & & $\mathrm{x}$ & $\mathrm{x}$ & & $\mathrm{x}$ & $\mathrm{x}$ & $\mathrm{x}$ & & & & \\
\hline Parênquima aliforme & & & & & $\mathrm{x}$ & & & & & & & & & \\
\hline Parênquima aliforme confluente & & & & & $\mathrm{x}$ & $\mathrm{x}$ & & $\mathrm{x}$ & & & $\mathrm{x}$ & & & \\
\hline Parênquima apotraqueal difuso & $\mathrm{x}$ & $\mathrm{x}$ & & $\mathrm{x}$ & $\mathrm{x}$ & & & $\mathrm{x}$ & & & & & $\mathrm{x}$ & \\
\hline Parênquima apotraqueal difuso a agregado & $\mathrm{x}$ & & & $\mathrm{x}$ & & & & & & & & & $\mathrm{x}$ & \\
\hline Parênquima em faixas & & & & $\mathrm{x}$ & & $\mathrm{x}$ & & & & & $\mathrm{x}$ & & & \\
\hline Parênquima em faixas marginais & & & & & & $\mathrm{x}$ & & & & & $\mathrm{x}$ & & & $\mathrm{x}$ \\
\hline Parênquima paratraqueal escasso & $\mathrm{x}$ & $\mathrm{x}$ & & & & & $\mathrm{x}$ & & $\mathrm{x}$ & $\mathrm{x}$ & & & $\mathrm{x}$ & $\mathrm{x}$ \\
\hline Parênquima paratraqueal vasicêntrico & & & & & $\mathrm{x}$ & & & $\mathrm{x}$ & $\mathrm{x}$ & $\mathrm{x}$ & & $\mathrm{x}$ & & \\
\hline Parênquima paratraqueal vasicêntrico e confluente & & & & & & & & & & & & $\mathrm{x}$ & & \\
\hline Placa de perfuração escalariforme & & $\mathrm{x}$ & & & & & & $\mathrm{x}$ & $\mathrm{x}$ & $\mathrm{x}$ & & & & \\
\hline Placa de perfuração simples & $\mathrm{x}$ & $\mathrm{x}$ & $\mathrm{x}$ & $\mathrm{x}$ & $\mathrm{x}$ & $\mathrm{x}$ & $\mathrm{x}$ & $\mathrm{x}$ & $\mathrm{x}$ & $\mathrm{x}$ & $\mathrm{x}$ & $\mathrm{x}$ & $\mathrm{x}$ & $\mathrm{x}$ \\
\hline Pontoações Intervasculares alternas & $\mathrm{x}$ & $\mathrm{x}$ & $\mathrm{x}$ & $\mathrm{x}$ & $\mathrm{x}$ & $\mathrm{X}$ & $\mathrm{x}$ & $\mathrm{x}$ & $\mathrm{x}$ & $\mathrm{X}$ & $\mathrm{x}$ & $\mathrm{x}$ & $\mathrm{x}$ & $\mathrm{x}$ \\
\hline Presença de células de amido & & & & & & $\mathrm{x}$ & & $\mathrm{x}$ & $\mathrm{x}$ & & & & & \\
\hline Presença de células envolventes & & & & & & & & $\mathrm{x}$ & & & & & & \\
\hline Presença de células latericuriformes & & & & & & & & $\mathrm{x}$ & & & & & & \\
\hline Presença de conteúdo no parênquima axial & & & & & & & & $\mathrm{x}$ & & & & & & \\
\hline Presença de conteúdo nos raios & & & & $\mathrm{x}$ & & & & $\mathrm{x}$ & $\mathrm{x}$ & & & & $\mathrm{x}$ & $\mathrm{x}$ \\
\hline Presença de conteúdo nos vasos & & & $\mathrm{x}$ & & & & & & & & & $\mathrm{x}$ & & $x$ \\
\hline
\end{tabular}




\begin{tabular}{|c|c|c|c|c|c|c|c|c|c|c|c|c|c|c|}
\hline & 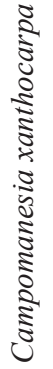 & 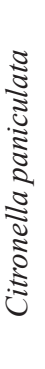 & 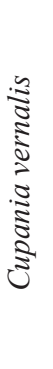 & 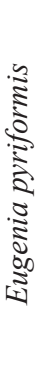 & $\begin{array}{l}5 \\
0 \\
0 \\
0 \\
0 \\
0 \\
0 \\
0 \\
0\end{array}$ & 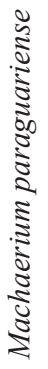 & 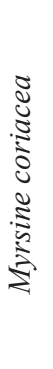 & 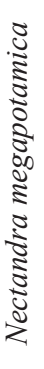 & 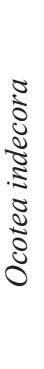 & 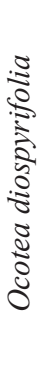 & 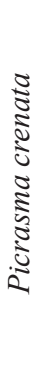 & 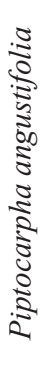 & 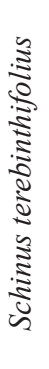 & 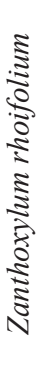 \\
\hline Presença de espessamento helicoidal no vaso & & & $\mathrm{x}$ & & & & & & & & & & $\mathrm{x}$ & \\
\hline Presença de tilos & & & & & & & & $\mathrm{X}$ & $\mathrm{x}$ & & & $\mathrm{x}$ & & \\
\hline Raios agregados & & $\mathrm{X}$ & & & & & & & & & & & & \\
\hline Raios heterocelulares & $\mathrm{x}$ & $\mathrm{X}$ & $\mathrm{X}$ & $\mathrm{X}$ & & $\mathrm{X}$ & $\mathrm{X}$ & $\mathrm{X}$ & $\mathrm{X}$ & $\mathrm{x}$ & $\mathrm{X}$ & $\mathrm{x}$ & $\mathrm{x}$ & $\mathrm{X}$ \\
\hline Raios homocelulares (Procumbentes) & & & & & $\mathrm{X}$ & & & & & & & & & \\
\hline Vasos arredondados & $\mathrm{X}$ & $\mathrm{x}$ & $\mathrm{x}$ & $\mathrm{X}$ & $\mathrm{X}$ & $\mathrm{X}$ & $\mathrm{x}$ & $\mathrm{X}$ & $\mathrm{X}$ & $\mathrm{X}$ & $\mathrm{x}$ & $\mathrm{X}$ & $\mathrm{X}$ & $\mathrm{X}$ \\
\hline Vasos solitários & $\mathrm{X}$ & & & & & & & & & & & & & \\
\hline Vasos solitários e múltiplos de 2 a 3 & & & & $\mathrm{X}$ & & & & & & & & & & \\
\hline Vasos solitários e múltiplos de 2 a 4 & & $\mathrm{X}$ & $\mathrm{x}$ & & & & & & $\mathrm{X}$ & & $\mathrm{x}$ & & & \\
\hline Vasos solitários e múltiplos de 2 a 5 & & & & & $\mathrm{x}$ & $\mathrm{x}$ & & $\mathrm{X}$ & & $\mathrm{X}$ & & & & $\mathrm{X}$ \\
\hline Vasos solitários e múltiplos de 2 a 9 & & & & & & & $\mathrm{x}$ & & & & & $\mathrm{x}$ & $\mathrm{x}$ & \\
\hline
\end{tabular}

(C. paniculata)(Fig. 3b), estratificação do parênquima axial, das fibras, dos vasos e dos raios (M. paraguariense)(Fig. 3f) e estratificação dos raios menores, do parênquima axial e das fibras (P. crenata)(Fig. 3k). De todas as espécies, a que mais apresentou características únicas foi a Nectandra megapotamica, sendo elas: presença de células envolventes, latericuliformes, conteúdo no parênquima axial e canais intercelulares (Fig. 2h).

A seguir, estão apresentados os valores médios para os elementos de vaso (Tab. 4), fibras (Tab. 5) e raios (Tab. 6). Utilizando estes resultados, foram confeccionados o dendrograma de Manhattan (Fig. 4) e a análise dos componentes principais (PCA). Posteriormente foram selecionadas as 3

Tabela 4 - Caracterização quantitativa dos vasos para todas as espécies.

Table 4 - Quantitative characterization of vessels for all species.

\begin{tabular}{|c|c|c|c|c|c|c|}
\hline Espécie & & VasoF & $\begin{array}{c}\text { VasoC } \\
(\mu \mathrm{m})\end{array}$ & $\begin{array}{c}\text { VasoD } \\
(\mu \mathrm{m})\end{array}$ & $\begin{array}{c}\text { PontRV } \\
(\mu \mathrm{m})\end{array}$ & $\begin{array}{c}\text { PontV } \\
(\mu \mathrm{m})\end{array}$ \\
\hline \multirow{4}{*}{ Campomanesia xanthocarpa } & Média & 6,52 & 425,27 & 123,11 & 2,66 & 4,57 \\
\hline & Desv. Pad & 2,07 & 121,05 & 25,04 & 0,91 & 0,60 \\
\hline & Máxima & 12,00 & 666,67 & 174,54 & 5,35 & 6,16 \\
\hline & Mínima & 3,00 & 44,79 & 46,24 & 1,37 & 3,11 \\
\hline \multirow{4}{*}{ Citronella paniculata } & Média & 14,23 & 1053,69 & 72,06 & 6,17 & 5,89 \\
\hline & Desv. Pad & 3,13 & 258,59 & 22,45 & 1,73 & 1,35 \\
\hline & Máxima & 22,00 & 1682,17 & 140,59 & 10,84 & 10,08 \\
\hline & Mínima & 7,00 & 410,62 & 18,64 & 3,82 & 3,67 \\
\hline
\end{tabular}




\begin{tabular}{|c|c|c|c|c|c|c|}
\hline Espécie & & VasoF & $\begin{array}{c}\text { VasoC } \\
(\mu \mathrm{m})\end{array}$ & $\begin{array}{c}\text { VasoD } \\
(\mu \mathrm{m})\end{array}$ & $\begin{array}{c}\text { PontRV } \\
(\mu \mathrm{m})\end{array}$ & $\begin{array}{c}\text { PontV } \\
(\mu \mathrm{m})\end{array}$ \\
\hline \multirow{4}{*}{ Cupania vernalis } & Média & 8,21 & 374,27 & 88,25 & 3,37 & 3,66 \\
\hline & Desv. Pad & 3,08 & 87,39 & 23,88 & 0,50 & 0,56 \\
\hline & Máxima & 16,00 & 594,77 & 151,12 & 4,49 & 4,88 \\
\hline & Mínima & 2,00 & 203,74 & 35,71 & 2,14 & 2,60 \\
\hline \multirow{4}{*}{ Eugenia pyriformis } & Média & 128,79 & 412,80 & 33,86 & 2,92 & 3,46 \\
\hline & Desv. Pad & 15,48 & 113,79 & 5,41 & 0,48 & 0,71 \\
\hline & Máxima & 159,00 & 704,23 & 51,70 & 4,21 & 5,81 \\
\hline & Mínima & 102,00 & 174,13 & 21,68 & 1,86 & 2,14 \\
\hline \multirow{4}{*}{ Inga vera } & Média & 3,51 & 316,41 & 141,20 & 5,85 & 6,46 \\
\hline & Desv. Pad & 1,46 & 85,52 & 28,57 & 1,18 & 0,89 \\
\hline & Máxima & 10,00 & 493,38 & 209,26 & 9,52 & 8,98 \\
\hline & Mínima & 1,00 & 110,36 & 69,48 & 3,67 & 4,51 \\
\hline \multirow{4}{*}{ Machaerium paraguariense } & Média & 3,88 & 177,21 & 108,30 & 5,51 & 6,95 \\
\hline & Desv. Pad & 1,96 & 21,55 & 26,49 & 1,64 & 1,30 \\
\hline & Máxima & 11,00 & 236,23 & 193,60 & 9,63 & 10,24 \\
\hline & Mínima & 1,00 & 110,34 & 47,79 & 2,73 & 3,51 \\
\hline \multirow{4}{*}{ Myrsine coriacea } & Média & 15,98 & 366,26 & 77,42 & 5,28 & 5,83 \\
\hline & Desv. Pad & 3,45 & 85,65 & 15,49 & 1,06 & 0,63 \\
\hline & Máxima & 25,00 & 611,94 & 109,12 & 8,82 & 7,47 \\
\hline & Mínima & 9,00 & 178,15 & 39,88 & 2,91 & 3,63 \\
\hline \multirow{4}{*}{ Nectandra megapotamica } & Média & 8,13 & 481,65 & 112,85 & 11,67 & 9,62 \\
\hline & Desv. Pad & 1,82 & 104,93 & 36,18 & 3,26 & 1,64 \\
\hline & Máxima & 12,00 & 796,62 & 180,23 & 18,48 & 12,74 \\
\hline & Mínima & 4,00 & 250,80 & 26,47 & 5,70 & 5,70 \\
\hline \multirow{4}{*}{ Ocotea indecora } & Média & 6,08 & 504,20 & 144,66 & 11,12 & 10,55 \\
\hline & Desv. Pad & 2,59 & 123,76 & 31,44 & 2,27 & 1,00 \\
\hline & Máxima & 13,00 & 840,14 & 214,27 & 18,75 & 12,98 \\
\hline & Mínima & 2,00 & 193,16 & 58,35 & 7,15 & 7,76 \\
\hline \multirow{4}{*}{ Ocotea diospyrifolia } & Média & 6,93 & 503,70 & 122,22 & 10,37 & 10,23 \\
\hline & Desv. Pad & 2,21 & 119,13 & 23,56 & 2,65 & 2,02 \\
\hline & Máxima & 15,00 & 781,34 & 172,68 & 16,24 & 14,01 \\
\hline & Mínima & 2,00 & 219,70 & 52,78 & 5,23 & 5,31 \\
\hline \multirow{4}{*}{ Picrasma crenata } & Média & 5,93 & 296,31 & 98,92 & 3,18 & 3,04 \\
\hline & Desv. Pad & 2,29 & 51,20 & 26,07 & 0,52 & 0,49 \\
\hline & Máxima & 11,00 & 422,05 & 154,17 & 4,78 & 4,81 \\
\hline & Mínima & 1,00 & 110,21 & 47,21 & 2,11 & 1,86 \\
\hline \multirow{4}{*}{ Piptocarpha angustifolia } & Média & 6,63 & 303,58 & 110,61 & 5,09 & 4,94 \\
\hline & Desv. Pad & 2,54 & 61,36 & 20,86 & 0,72 & 0,79 \\
\hline & Máxima & 14,00 & 467,05 & 164,71 & 7,15 & 6,89 \\
\hline & Mínima & 1,00 & 120,95 & 58,84 & 2,92 & 2,86 \\
\hline
\end{tabular}


Tabela 5 - Caracterização quantitativa das fibras para todas as espécies.

Table 5 - Quantitative characterization of fibers for all species.

\begin{tabular}{|c|c|c|c|c|c|}
\hline Espécie & & FibraC $(\mu \mathrm{m})$ & FibraLa $(\mu \mathrm{m})$ & FibraLu $(\mu \mathrm{m})$ & Fibra EP $(\mu \mathrm{m})$ \\
\hline \multirow{4}{*}{ Campomanesia xanthocarpa } & Média & 1742,27 & 18,85 & 7,94 & 5,45 \\
\hline & Desv. Pad & 186,60 & 3,47 & 1,82 & 1,49 \\
\hline & Máxima & 2311,63 & 27,94 & 13,36 & 9,12 \\
\hline & Mínima & 1297,82 & 9,61 & 4,31 & 2,11 \\
\hline \multirow{4}{*}{ Citronella paniculata } & Média & 2637,06 & 30,52 & 11,40 & 9,56 \\
\hline & Desv. Pad & 360,15 & 5,88 & 4,96 & 2,75 \\
\hline & Máxima & 3475,68 & 44,42 & 26,67 & 15,69 \\
\hline & Mínima & 1842,47 & 17,50 & 2,66 & 3,26 \\
\hline \multirow{4}{*}{ Cupania vernalis } & Média & 934,34 & 18,28 & 10,68 & 3,80 \\
\hline & Desv. Pad & 83,20 & 3,09 & 3,03 & 0,99 \\
\hline & Máxima & 1132,65 & 30,31 & 23,11 & 6,40 \\
\hline & Mínima & 754,40 & 11,32 & 3,47 & 1,44 \\
\hline \multirow{4}{*}{ Eugenia pyriformis } & Média & 1247,92 & 17,37 & 6,95 & 5,21 \\
\hline & Desv. Pad & 134,45 & 2,63 & 2,12 & 0,95 \\
\hline & Máxima & 1616,03 & 23,61 & 14,25 & 7,74 \\
\hline & Mínima & 912,79 & 11,24 & 2,99 & 2,46 \\
\hline \multirow{4}{*}{ Inga vera } & Média & 1190,45 & 19,72 & 12,15 & 3,78 \\
\hline & Desv. Pad & 156,38 & 4,23 & 4,42 & 1,07 \\
\hline & Máxima & 1739,10 & 32,65 & 26,21 & 6,79 \\
\hline & Mínima & 876,74 & 11,24 & 2,53 & 1,43 \\
\hline \multirow{4}{*}{ Machaerium paraguariense } & Média & 1112,60 & 17,48 & 9,91 & 3,79 \\
\hline & Desv. Pad & 98,75 & 3,59 & 3,00 & 0,82 \\
\hline & Máxima & 1358,26 & 28,19 & 16,53 & 7,10 \\
\hline & Mínima & 858,90 & 9,92 & 3,49 & 1,94 \\
\hline \multirow{4}{*}{ Myrsine coriacea } & Média & 858,19 & 22,88 & 9,25 & 6,82 \\
\hline & Desv. Pad & 108,77 & 4,69 & 3,69 & 1,98 \\
\hline & Máxima & 1152,57 & 38,26 & 20,11 & 11,65 \\
\hline & Mínima & 575,38 & 11,33 & 2,17 & 1,97 \\
\hline \multirow{4}{*}{ Nectandra megapotamica } & Média & 1213,87 & 20,26 & 12,75 & 3,75 \\
\hline & Desv. Pad & 179,36 & 4,45 & 3,80 & 0,94 \\
\hline & Máxima & 1889,77 & 29,96 & 22,08 & 5,75 \\
\hline & Mínima & 862,54 & 7,15 & 2,05 & 1,26 \\
\hline \multirow{4}{*}{ Ocotea indecora } & Média & 1295,65 & 24,03 & 14,92 & 4,55 \\
\hline & Desv. Pad & 177,72 & 5,40 & 5,41 & 1,40 \\
\hline & Máxima & 1778,24 & 45,04 & 37,94 & 8,96 \\
\hline & Mínima & 697,75 & 14,19 & 4,69 & 2,16 \\
\hline \multirow{4}{*}{ Ocotea diospyrifolia } & Média & 1494,60 & 22,58 & 12,44 & 5,10 \\
\hline & Desv. Pad & 195,54 & 4,69 & 4,59 & 1,35 \\
\hline & Máxima & 1978,40 & 33,98 & 25,58 & 8,87 \\
\hline & Mínima & 988,94 & 12,49 & 2,86 & 2,76 \\
\hline \multirow{4}{*}{ Picrasma crenata } & Média & 1136,54 & 20,34 & 13,18 & 3,58 \\
\hline & Desv. Pad & 108,76 & 5,37 & 4,59 & 0,90 \\
\hline & Máxima & 1394,71 & 32,41 & 23,68 & 6,69 \\
\hline & Mínima & 857,74 & 7,78 & 1,86 & 1,73 \\
\hline
\end{tabular}




\begin{tabular}{cccccc}
\hline Espécie & & FibraC $(\boldsymbol{\mu m})$ & FibraLa $(\boldsymbol{\mu m})$ & FibraLu $(\boldsymbol{\mu m})$ & Fibra EP $(\boldsymbol{\mu m})$ \\
\hline \multirow{3}{*}{ Piptocarpha angustifolia } & Média & 958,38 & 26,94 & 19,01 & 3,97 \\
& Desv. Pad & 116,66 & 5,17 & 5,16 & 0,81 \\
& Máxima & 1289,58 & 44,08 & 37,25 & 6,58 \\
& Mínima & 666,19 & 13,04 & 6,44 & 1,95 \\
& Média & 733,24 & 18,20 & 10,63 & 3,79 \\
Schinus terebinthifolius & Desv. Pad & 81,97 & 3,45 & 2,94 & 0,87 \\
& Máxima & 969,29 & 27,18 & 16,90 & 6,45 \\
& Mínima & 550,37 & 11,18 & 4,54 & 1,23 \\
& Média & 1024,49 & 18,98 & 11,66 & 3,66 \\
Zanthoxylum rhoifolium & Desv. Pad & 105,78 & 3,72 & 3,71 & 0,89 \\
& Máxima & 1431,84 & 30,00 & 20,64 & 5,81 \\
& Mínima & 766,45 & 12,10 & 2,42 & 1,61 \\
\hline
\end{tabular}

Tabela 6 - Caracterização quantitativas dos raios para todas as espécies. Table 6 - Quantitative characterization of rays for all species.

\begin{tabular}{|c|c|c|c|c|c|c|}
\hline Espécie & & RaioCM $(\mu \mathrm{m})$ & RaioEM $(\mu \mathrm{m})$ & RaioCN & RaioEN & RaioF \\
\hline \multirow{5}{*}{ Campomanesia xanthocarpa } & Média & 239,29 & 32,99 & 13,76 & 2,50 & 7,74 \\
\hline & Desv. Pad & 110,29 & 11,64 & 8,62 & 1,29 & 1,26 \\
\hline & Máxima & 648,90 & 55,04 & 39,00 & 4,00 & 11,00 \\
\hline & Mínima & 60,23 & 9,04 & 2,00 & 1,00 & 6,00 \\
\hline & Média & 3152,08 & 304,92 & 129,33 & 15,10 & 2,11 \\
\hline \multirow{4}{*}{ Citronella paniculata } & Desv. Pad & 1627,75 & 82,13 & 32,59 & 2,25 & 0,70 \\
\hline & Máxima & 8766,31 & 547,80 & 194,00 & 19,00 & 4,00 \\
\hline & Mínima & 609,15 & 143,10 & 50,00 & 7,00 & 1,00 \\
\hline & Média & 233,33 & 16,10 & 12,07 & 1,21 & 15,89 \\
\hline \multirow{4}{*}{ Cupania vernalis } & Desv. Pad & 117,36 & 3,88 & 5,69 & 0,41 & 2,68 \\
\hline & Máxima & 561,54 & 28,84 & 29,00 & 2,00 & 22,00 \\
\hline & Mínima & 38,67 & 9,04 & 4,00 & 1,00 & 10,00 \\
\hline & Média & 158,58 & 17,92 & 9,94 & 1,91 & 12,85 \\
\hline \multirow{4}{*}{ Eugenia pyriformis } & Desv. Pad & 66,09 & 5,49 & 4,17 & 0,64 & 2,08 \\
\hline & Máxima & 352,36 & 34,48 & 22,00 & 3,00 & 18,00 \\
\hline & Mínima & 42,87 & 7,56 & 3,00 & 1,00 & 9,00 \\
\hline & Média & 173,12 & 19,47 & 10,57 & 1,73 & 7,39 \\
\hline \multirow{4}{*}{ Inga vera } & Desv. Pad & 69,43 & 7,49 & 3,90 & 0,65 & 2,28 \\
\hline & Máxima & 469,44 & 42,17 & 20,00 & 3,00 & 14,00 \\
\hline & Mínima & 46,78 & 6,43 & 2,00 & 1,00 & 3,00 \\
\hline & Média & 127,68 & 32,69 & 7,91 & 2,62 & 6,18 \\
\hline \multirow{4}{*}{ Machaerium paraguariense } & Desv. Pad & 14,79 & 9,53 & 1,30 & 0,57 & 2,16 \\
\hline & Máxima & 167,44 & 66,33 & 14,00 & 4,00 & 10,00 \\
\hline & Mínima & 91,88 & 13,42 & 4,00 & 1,00 & 1,00 \\
\hline & Média & 3539,06 & 114,61 & 127,33 & 13,06 & 2,23 \\
\hline \multirow{3}{*}{ Myrsine coriacea } & Desv. Pad & 1255,85 & 87,91 & 25,55 & 1,34 & 0,69 \\
\hline & Máxima & 6433,81 & 255,71 & 169,00 & 16,00 & 4,00 \\
\hline & Mínima & 1061,18 & 0,13 & 40,00 & 10,00 & 1,00 \\
\hline
\end{tabular}




\begin{tabular}{|c|c|c|c|c|c|c|}
\hline Espécie & & RaioCM $(\mu \mathrm{m})$ & RaioEM $(\mu \mathrm{m})$ & RaioCN & RaioEN & RaioF \\
\hline \multirow{4}{*}{ Nectandra megapotamica } & Média & 334,75 & 33,56 & 13,56 & 2,75 & 4,65 \\
\hline & Desv. Pad & 91,27 & 6,85 & 5,25 & 0,72 & 0,88 \\
\hline & Máxima & 586,66 & 53,41 & 25,00 & 4,00 & 7,00 \\
\hline & Mínima & 141,40 & 18,32 & 4,00 & 2,00 & 3,00 \\
\hline \multirow{4}{*}{ Ocotea indecora } & Média & 463,83 & 51,92 & 12,83 & 3,05 & 4,95 \\
\hline & Desv. Pad & 150,46 & 10,22 & 5,06 & 0,73 & 1,36 \\
\hline & Máxima & 948,47 & 80,74 & 30,00 & 4,00 & 8,00 \\
\hline & Mínima & 140,86 & 29,47 & 5,00 & 1,00 & 2,00 \\
\hline \multirow{4}{*}{ Ocotea diospyrifolia } & Média & 414,20 & 58,37 & 16,29 & 3,79 & 5,11 \\
\hline & Desv. Pad & 139,52 & 13,52 & 6,67 & 0,87 & 0,96 \\
\hline & Máxima & 879,56 & 90,36 & 30,00 & 6,00 & 7,00 \\
\hline & Mínima & 169,17 & 25,52 & 3,00 & 2,00 & 3,00 \\
\hline \multirow{4}{*}{ Picrasma crenata } & Média & 288,16 & 48,57 & 12,16 & 2,89 & 4,35 \\
\hline & Desv. Pad & 131,17 & 17,90 & 6,61 & 1,22 & 1,23 \\
\hline & Máxima & 656,64 & 93,69 & 37,00 & 5,00 & 7,00 \\
\hline & Mínima & 117,24 & 12,42 & 3,00 & 1,00 & 1,00 \\
\hline \multirow{4}{*}{ Piptocarpha angustifolia } & Média & 625,28 & 62,70 & 21,79 & 3,93 & 4,50 \\
\hline & Desv. Pad & 284,61 & 18,09 & 9,93 & 0,87 & 0,94 \\
\hline & Máxima & 1616,53 & 104,80 & 55,00 & 6,00 & 7,00 \\
\hline & Mínima & 135,04 & 20,20 & 7,00 & 2,00 & 2,00 \\
\hline \multirow{4}{*}{ Schinus terebinthifolius } & Média & 223,72 & 28,83 & 13,75 & 2,99 & 8,60 \\
\hline & Desv. Pad & 63,48 & 7,40 & 3,93 & 0,64 & 1,77 \\
\hline & Máxima & 450,04 & 50,55 & 26,00 & 4,00 & 14,00 \\
\hline & Mínima & 115,67 & 14,86 & 6,00 & 2,00 & 5,00 \\
\hline \multirow{4}{*}{ Zanthoxylum rhoifolium } & Média & 207,28 & 28,86 & 12,23 & 2,78 & 4,44 \\
\hline & Desv. Pad & 71,23 & 10,80 & 4,75 & 0,71 & 0,98 \\
\hline & Máxima & 355,39 & 57,54 & 29,00 & 4,00 & 6,00 \\
\hline & Mínima & 62,44 & 6,88 & 4,00 & 1,00 & 2,00 \\
\hline
\end{tabular}

características de cada eixo que mais auxiliam a explicar a variação dos dados entre as espécies (Tab. 7, Fig. 5).

Observou-se que para os indivíduos avaliados o diâmetro do vaso, a altura do raio em micrômetros e em número de células, a largura do raio em micrômetros, as pontoações intervasculares e as raio-vasculares são as principais características que contribuem para explicar a variação dos dados.

Na Figura 5, pode-se observar a distribuição gráfica dos seis parâmetros mais relevantes para as principais características anatômicas que variam entre as espécies. Ao avaliar o dendrograma, pode-se perceber que foram formados dois grandes grupos. Utilizando o PCA, é possível determinar que inicialmente as espécies diferenciaram-se devido os altos valores encontrados para as variáveis dos raios.

Assim, considerando o PCA, pode-se afirmar que as espécies $C$. paniculata e $M$. coriacea, estão distantes das demais espécies por apresentarem raios longos e largos. Ainda, utilizando as características anatômicas, é possível diferenciar estas espécies uma vez que a $M$. coriacea apresenta somente placa de perfuração simples e a $C$. paniculata também apresenta placa de perfuração escalariforme.

Pode-se perceber também que do grupo formado pelas espécies com raios menores, a $E$. pyriformis apresenta os menores diâmetros de vasos. Subsequentemente, são formados dois conjuntos, um composto por espécies de Lauraceae $(N$. megapotamica, $O$, indecora, $O$. diospyrifolia) e o 
Eugenia pyriformis

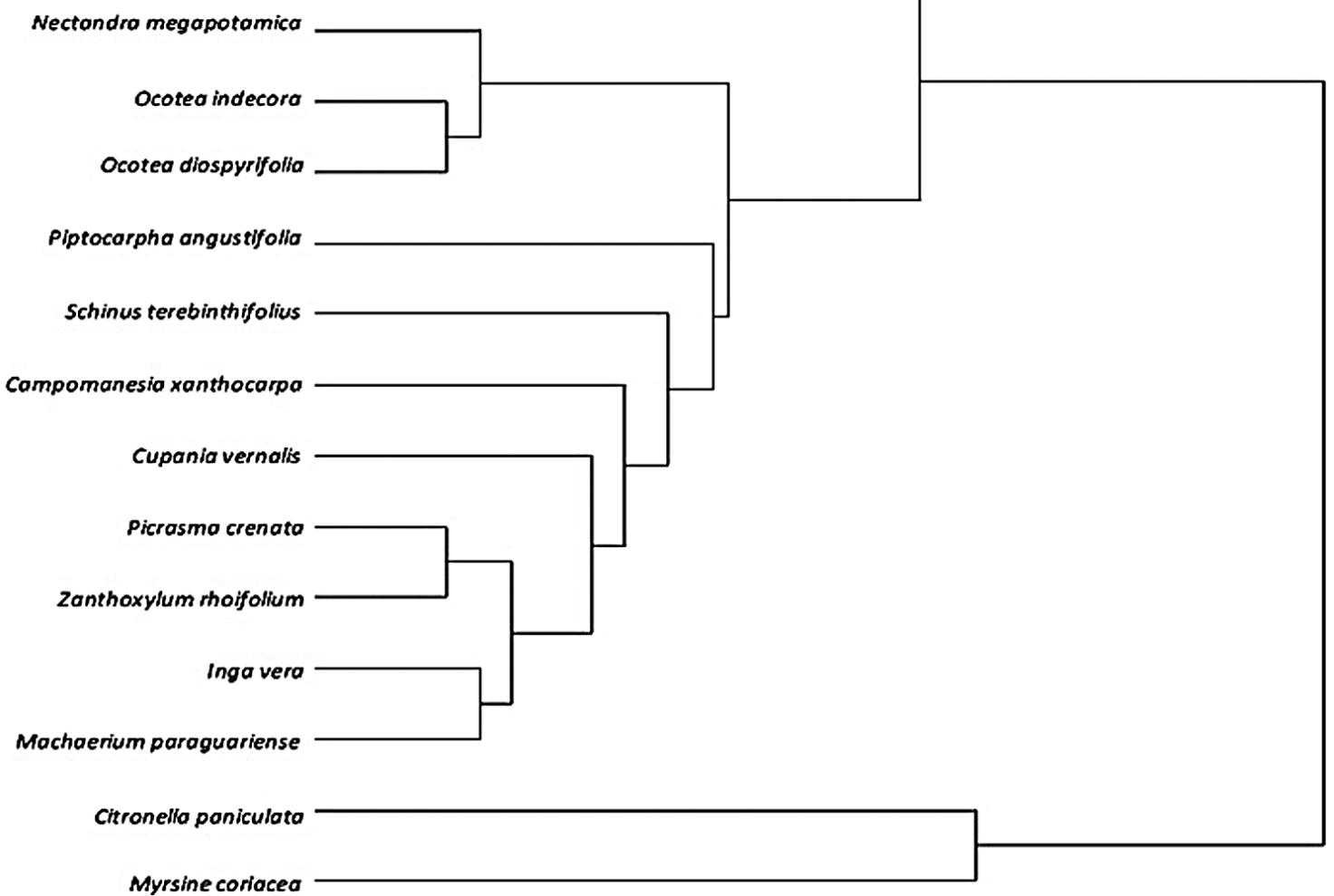

Figura 4 - Dendrograma de similaridade de Manhattan para todas as espécies caracterizadas.

Figure 4 - Manhattan similarity dendrogram for all species.

Tabela 7 - Resumo dos valores encontrados na Análise de Componentes Principais considerando as variáveis comprimento e espessura dos raios em micrômetros, comprimento dos raios em número de células, diâmetros dos vasos, pontoações intervasculares e pontoações raio-vasculares.

Table 7 - Summary of the values found in the Analysis of Principal Components considering the variables length and thickness of rays in micrometers, length of rays in number of cells, vessel diameters, vascular and ray-vascular pits.

\begin{tabular}{ccc}
\hline Variável & PC 1 & PC 2 \\
\hline VasoD & $-0,27$ & 0,35 \\
RaioCM & 0,55 & 0,16 \\
RaioEM & 0,51 & 0,20 \\
RaioCN & 0,56 & 0,14 \\
PontRV & $-0,13$ & 0,63 \\
PontV & $-0,16$ & 0,63 \\
Autovalores & 2,91 & 2,18 \\
Variância & $49 \%$ & $36 \%$ \\
\hline
\end{tabular}

outro formado pelas demais espécies caracterizadas. O agrupamento de espécies da mesma família também foi observado por Lobão et al. (2011), uma vez que espécies com proximidade genética tendem a apresentar características semelhantes.

Utilizando o PCA é possível afirmar que as Lauraceae se destacam das demais devido ao alto valor encontrado para o diâmetro médio das pontoações intervasculares e raio-vasculares. Ainda, a espécie $N$. megapotamica difere das espécies do gênero Ocotea pela presença de células envolventes, latericuliformes, conteúdo no parênquima axial e canais intercelulares.

Considerando o subgrupo formado pelas espécies com raios de pequenas dimensões, maiores diâmetros de vasos, pequenas pontoações intervasculares e raio-vasculares, não é possível realizar o agrupamento das espécies utilizando somente as características do PCA. Portanto, para evidenciar as diferenças entre as espécies foram utilizadas as características qualitativas. A 


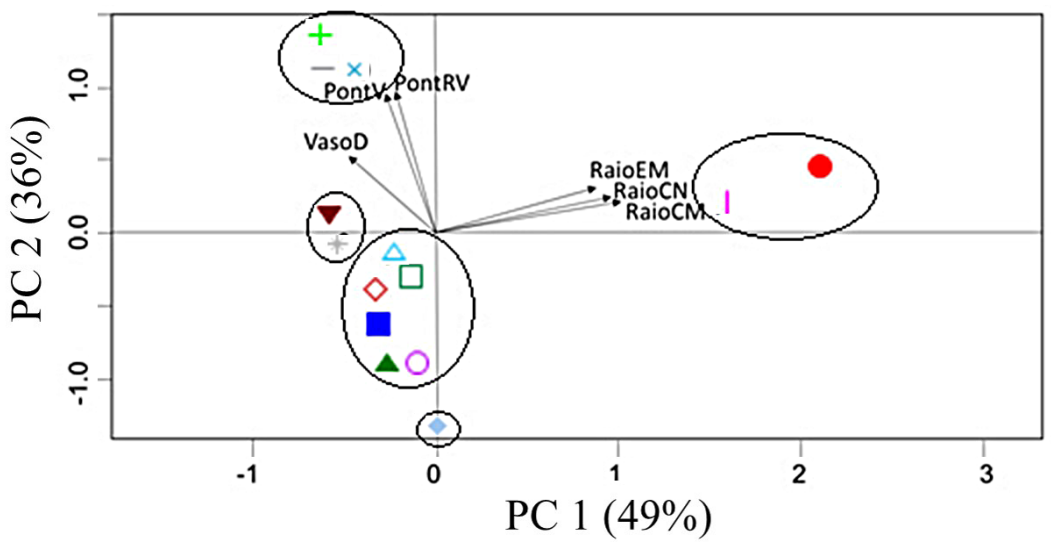

Campomanesia xanthocarpa

Citronella paniculata

- Cupania vernalis

$\diamond$ Eugenia pyriformis

$\nabla$ Inga vera

* Machaerium paraguariense

I Myrsine coriacea

- Nectandra megapotamica

+ Ocotea diospyrifolia

$\times$ Ocotea indecora

- Picrasma crenata

$\square$ Piptocarpha angustifolia

$\triangle$ Schinus terebinthifolius

$\diamond$ Zanthoxylum rhoifolium

Figura 5 - Escores e autovetores da análise dos componentes principais considerando os fatores, comprimento e espessura dos raios em micrômetros, comprimento dos raios em número de células, diâmetros dos vasos, pontoações intervasculares e pontoações raio-vasculares.

Figure 5 - Scores and eigenvectors of principal components analyses considering the factors, length and thickness of rays in micrometers, length of rays in number of cells, vessel diameters, vascular and ray-vascular pits.

espécie P. angustifolia diferencia-se das demais por apresentar parênquima vasicêntrico confluente, a $S$. terebinthifolius apresenta canais radiais e a $C$. xanthocarpa possui a distribuição diagonal dos elementos de vasos.

São formados então dois novos subgrupos, diferenciados pela ausência de fibras septadas nas espécies $P$. crenata (com anéis de difícil reconhecimento) e $Z$. rhoifolium (anéis distintos). As espécies com fibras septadas são a I. vera e $M$. paraguariense, que se diferencia pela estratificação dos seus elementos anatômicos.

\section{Considerações Finais}

$\mathrm{Na}$ caracterização anatômica, observouse que as espécies apresentam características comuns como a porosidade difusa, elementos vasculares arredondados e com pontoações intervasculares alternas. Além disso, foram observadas características únicas, como a distribuição diagonal dos vasos, estratificação dos elementos anatômicos, presença de células envolventes, latericuliformes e substâncias oleaginosas no parênquima axial.

Quanto à similaridade das espécies, observouse a divisão das mesmas pelas dimensões dos raios, vasos e pontoções. Corroborando com este resultado, na Análise dos Componentes Principais (PCA), destacaram-se o diâmetro do vaso, a altura e largura do raio em micrômetros, a altura do raio em número de células, as pontoações da intervasculares e raio-vasculares.
Assim, pode-se concluir as espécies da Floresta Ombrófila Mista, que ocorrem naturalmente na região do Planalto Catarinense e foram caracterizadas neste estudo, apresentam grande diversidade de estrutura anatômica. No entanto, ainda assim podemos agrupar espécies e distingui-las com base em características anatômicas quantitativas e qualitativas.

\section{Referências}

Avila GR \& Oliveira JM (2017) Lauraceae: A promising family for the advance of neotropical dendrochronology. Dendrochronologia 44: 103-116.

Brandes AFDN \& Barros CF (2008) Wood anatomy of eight liana species of Leguminosae family from Atlantic Rain Forest. Acta Botanica Brasilica 22: 465-480.

Britez RD, Reissmann CB, Silva SM \& Santos Filho AD (1992) Deposição estacional de serapilheira e macronutrientes em uma floresta de Araucária, São Mateus do Sul, Paraná. Revista do Instituto Florestal 4: 766-772.

Burger LM \& Richter HG 1991. Anatomia da madeira. Nobel, São Paulo. 154 p.

Carlquist S (2001) Comparative wood anatomy: systematic. Ecological, and evolutionary aspects of dicotyledon wood. Springer Science \& Business Media, Berlin Heidelberg. 448p.

Cosmo NL, Kuniyoshi YS \& Botosso PC (2010) Anatomia da madeira de Sebastiana commersoniana (Baillon) Smith \& Downs (Euphorbiaceae): aspectos funcionais e ecológicos. Acta Botanica Brasilica 24: 747-755. 
Cury G (2001) Descrição da estrutura anatômica do lenho e sua aplicação na identificação de espécies arbóreas do cerrado e da mata atlântica do estado de São Paulo. Tese de Doutorado. Universidade de São Paulo, São Paulo. 178 p.

Eisenlohr PV \& Oliveira Filho AT (2014) Tree species composition in areas of Atlantic Forest in southeastern Brazil is consistent with a new system for classifying the vegetation of South America. Acta Botanica Brasilica 28: 227-233.

Franklin GL (1945) Preparation of thin sections of synthetic resins and wood-resin composites, and a new macerating method for wood. Nature 155: 51.

Guerra MP, Silveira V, Reis MD \& Schneider L (2002) Exploração, manejo e conservação da araucária (Araucaria angustifolia). Sustentável Mata Atlântica: a exploração de seus recursos florestais. SENAC, São Paulo. Pp. 85-101.

Hueck K (1972) As florestas da América do Sul. Polígono, São Paulo. 239p.

IAWA - International Association of Wood Anatomists Committee (1989) List of microscope features for hardwood identification. IAWA Bulletin 10: 219-332.

Inoue MT, Rodenjan CV \& Kunijoski YS (1984) Projeto madeira de Paraná. Fundação de Pesquisas Florestais do Paraná, Curitiba. 260p.

Kraus JE \& Arduin M (1997) Manual básico de métodos em morfologia vegetal. Edur, Seropédica. 198p.

Lobão MS, Castro VRD, Rangel A, Sarto C, Tomazello Filho M, Silva Júnior FGD \& Bermudez MARC (2011) Agrupamento de espécies florestais por análises univariadas e multivariadas das características anatômica, física e química das suas madeiras. Scientia Forestalis 39: 469-477.

Lobão MS, Costa D, Ferreira A, Sette C, Carvalho I, \& Tomazello M (2010) Agrupamento de espécies florestais pela similaridade das características físicoanatômicas e usos da madeira. Cerne 16: 97-105.

Maiti R, Rodriguez HG, Para AC, Aruna Kumari CH \& Sarkar NC (2016). A comparative wood anatomy of 15 woody species in North-eastern Mexico. Forest Research 5: 2-8.
Marques JB, Callado CH, Rabelo GR, Silva Neto SJD \& Cunha MD (2015) Comparative wood anatomy of species of Psychotria L.(Rubiaceae) in Atlantic Rainforest remnants of Rio de Janeiro state, Brazil. Acta Botanica Brasilica 29: 433-444.

Marques PA, Araújo GUC, Barros CF \& Callado CH (2007) Anatomia do lenho de três espécies de Eugenia L.(Myrtaceae) de mata e restinga. Revista Brasileira de Biociências 5(supl 1): 801-803.

Nascimento ART, Longhi SJ \& Brena DA (2001) Estrutura e padrões de distribuição espacial de espécies arbóreas em uma amostra de Floresta Ombrófila Mista em Nova Prata, RS. Ciência Florestal 11: 105-119.

Oksanen J, Blanchet G, Kindt R, Legendre P, O'Hara RB, Simpson GL, Solymos P, Stevens MH \& Wagner H (2011) Vegan: community ecology package. R package version 1.17-6. Disponível em <https:// www.researchgate.net/publication/282247686_ Vegan_Community_Ecology_Package_R_package version_20-2>. Acesso em 18 outubro 2016.

Paula JE \& Alves JLH (2010) 922 madeiras nativas do Brasil: anatomia dendrologia dendrometria produção-uso. Cinco Continentes, Porto Alegre. $461 \mathrm{p}$.

R Core Team (2015) R: A language and environment for statistical computing. R Foundation for Statistical Computing, Vienna, Austria. Disponível em $<$ https:// www.r-project.org>. Acesso em 18 outubro 2016.

Siegloch AM, Marchiori JNC \& Santos SR (2013) Estudo comparativo do xilema secundário de três espécies ornamentais de Euphorbia. Floresta 43: 643-652.

Soffiatti P, Boeger MRT, Nisgoski S \& Kauai F (2016) Wood anatomical traits of the Araucaria Forest, Southern Brazil. Bosque 37: 21-31.

Souza AL, Hosokawa RT, Kirchner FF \& Machado SA (1990) Análises multivariadas para manejo de floresta natural na Reserva Florestal de Linhares, Espírito Santo: análises de agrupamento e discriminante. Revista Árvore 14: 85-101. 